\title{
Characteristies of Australian human enteric coronavirus-like particles: comparison with human respiratory coronavirus 229E and duodenal brush border vesicles
}

\author{
R. D. Schnagl ${ }^{1}$, Sharon Brookes ${ }^{1}$, Sue Medvedec ${ }^{1}$, \\ and Fran Morey ${ }^{2}$ \\ ${ }^{1}$ Department of Microbiology, La Trobe University, Bundoora, Victoria, and \\ ${ }^{2}$ Pathology Laboratory, Alice Springs Hospital, Alice Springs, \\ Northern Territory, Australia
}

Accepted July 27, 1987

\section{Summary}

The polypeptide profiles of highly purified coronavirus-like particles (CVLPs) proved to be very different from that of human respiratory coronavirus $229 \mathrm{E}$ and showed the particles not to be coronaviruses. Differences in polypeptide profiles and morphology between the CVLPs and duodenal brush border vesicles suggested that the CVLPs were also not such vesicles.

Although they shared some basic overall similarity, the polypeptide profiles of three different but possibly antigenically identical CVLP preparations from Central Australian Aborigines were very dissimilar in detail. At least 38,39 and 48 bands respectively were observed on the three profiles. At least 46 bands were visible on the polypeptide profile of CVLPs from a Vietnamese immigrant to Australia, and it also differed in detail from those of the Central Australian CVLPs.

Indications of antigenic difference were obtained between Central Australian CVLPs and CVLPs from India, Kiribati, South Africa and Vietnamese immigrants to Australia. Antigenic difference was also suggested between the Central Australian CVLPs and those from one distant location within Australia, but antigenic similarity with those from another was indicated.

\section{Introduction}

Since the detection in human stools of pleomorphic particles resembling coronaviruses in $1975[6,15]$ many further observations of such particles in faeces have been made. More recently it has become clearer 
that some of these particles are most probably true coronaviruses $[9,16]$, while others are likely to fit into the recently proposed torovirus group $[3,23]$.

Many other of these observed human enteric coronavirus-like particles (CVLPs), of types which appeared to be morphologically more dissimilar to the classical coronaviruses have, however, not yet been able to be adequately characterised [14]. Their characterisation has been made more difficult because, with perhaps one or two exceptions $[5,14]$, it has not yet been possible to grow them in culture. Further, their association with enteric disease has in many cases yet to be clearly established. Such particles have frequently been observed in stools from individuals without diarrhoea, as well as in stools from those with it [14]. In some instances they have been observed as frequently or even more frequently in those without diarrhoea $[18,19,21]$.

Suggestions have been made that at least some of these particles may not be viruses or even infectious agents, but may only be cell fragments. It has been suggested for example that they may be cell membrane fragments from the host gut wall [4], or vesicles from eucaryotic cells [7]. However, recently it was shown that in Australia serum antibody levels to one of the types of uncharacterised human enteric CVLP appeared to follow the observed excretion rates of the particles in the different populations tested. It was suggested that this gave support to the consideration of such particles as infectious agents [18].

In this paper we report on the preliminary characterisation of these human enteric CVLPs. As well as a comparison by negative contrast electron microscopy we undertook a comparison of the structural polypeptides of CVLPs from Australian Aborigines within those from the human respiratory coronavirus 229E (HRCV 229E) and duodenal brush border vesicles. Unfortunately comparisons with known animal enteric coronaviruses were not possible as these viruses are not permitted to be imported into Australia. We also report on apparent antigenic and structural polypeptide similarities and differences between CVLPs from the same and different areas.

\section{Materials and methods}

\section{Specimens and virus}

Central Australian CVLPs were purified from faecal specimens from Aboriginal children who had been admitted to Alice Springs Hospital for a variety of reasons in 1982, 1983 and 1984. Kalgoorlie (Western Australia) CVLPs were obtained from Aboriginal and European children admitted to Kalgoorlie Hospital with diarrhoea in 1975 and 1976. Fitzroy Crossing (Western Australia), Kiribati (Pacific Ocean) and South African (Lesotho) CVLPs originated from faecal specimens collected in medical audits in 1977, 1979, and 1985 , respectively. The South African specimens were kindly supplied by Professor 
B. D. Sehoub, Institute for Virology, Johannesburg. The Vietnamese CVLPs were purified from faecal specimens from Vietnamese immigrants to Australia. The faecal specimens were ones routinely collected immediately on the arrival of these immigrants in Australia in 1978. Or I. H. Holmes, Department of Microbiology, University of Melbourne, Australia kindly provided the faecal specimens from which the Indian (Vellore) CVLPs were purified.

The 229E strain of human respiratory coronavirus was obtained as the National Institutes of Health (Bethesda, MD, U.S.A.) research reference strain from Fairfield Hospital, Melbourne, Australia, as was the human embryonic lung (HEL) cell line in which the virus was grown.

Duodenal biopsy material was kindly provided by Dr G. L. Barnes, Gastroenterology Department, Royal Children's Hospital, Melbourne, Australia.

\section{Purification of CVLPs, HRCV 229E and duodenal brush border vesicles}

CVLPs were purified as outlined previously [17]. Briefly, faecal specimens were first clarified by centrifugation at $1,300 \times \mathrm{g}$ for 20 minutes, and after centrifugation of the supernatants at $100,000 \times \mathrm{g}$ for 1 hour the resultant pellets were layered onto a $10-50 \%$ $(\mathrm{v} / \mathrm{v})$ angiografin (Schering $\mathrm{AG}$, Berlin) gradient in phosphate buffered saline. The gradients were centrifuged at $75,000 \times \mathrm{g}$ for 6 hours and CVLP containing fractions further purified by centrifugation in a $30 \%(\mathrm{v} / \mathrm{v})$ glycerol $/ 50 \%(\mathrm{w} / \mathrm{w})$ potassium tartrate continuous gradient at $150,000 \times \mathrm{g}$ for 17 hours.

HRCV 229E was similarly purified except that after the virus-infected HEL cells had been frozen and thawed three times and this clarified by centrifugation at $2,000 \times \mathrm{g}$ for 30 minutes, the resultant supernatants were centrifuged at $82,000 \times \mathrm{g}$ for 1.25 hours. The resultant pellets were layered onto a $10-45 \%(\mathrm{v} / \mathrm{v})$ angiografin gradient in phosphate buffered saline and this centrifuged as above. Virus containing fractions were further purified by centrifugation in a $25 \%(\mathrm{v} / \mathrm{v})$ glycerol $/ 40 \%(\mathrm{w} / \mathrm{w})$ potassium tartrate continnous gradient at $110,000 \times \mathrm{g}$ for 17 hours.

All of the above purification procedures were carried out in the cold.

Duodenal brush border vesicles were purified from duodenal biopsy material according to the method of Kessler et al. [12]. The only exception was the addition of a further final purification step involving the centrifugation of the vesicle preparation on a $30 \%$ $(\mathrm{v} / \mathrm{v})$ glycerol $/ 50 \%(\mathrm{w} / \mathrm{w})$ potassium tartrate gradient exactly as used in the purification of the CVLPs.

\section{Buoyant density determination}

Buoyant density determinations were carried ont using a modification of the method of Kapikian et al. [11]. Purified preparations of CVLPs or HRCV 229E were layered onto $30-60 \%(\mathrm{w} / \mathrm{w})$ or $25-55 \%(\mathrm{w} / \mathrm{w})$ sucrose gradients respectively and these centrifuged at $150,000 \times \mathrm{g}$ for 17 hours at $4^{\circ} \mathrm{C}$. Gradients were then fractionated and refractive indices of the fractions determined. The buoyant densities were obtained from superimposed plots of the sucrose densities for each fraction and the relative numbers of partieles per fraction.

\section{Antiserum preparation}

For the preparation of antisera Balb/c mice were given four weekly intraperitoneal injections of purified CVLPs or HRCV 229E. The first CVLP or virus preparation only was mixed with an equal volume of Freund's incomplete adjuvant before injection. Mice were bled one week after the final injection.

\section{Electron microscopy}

For visualization by negative contrast electron microscopy small amounts of CVLP, HRCV $229 \mathrm{E}$ or duodenal brush border vesicle preparations were applied to copper grids 
which had been coated firstly with formvar and then carbon. Excess preparation was removed and the gxids then stained with one tenth saturated ammonium molybdate. A JEOL JEM-100S electron microscope operating at an accelerating voltage of 60,000 was used to view the grids.

\section{Immune electron microscopy}

For the determination of antigenic relationships between CVLPs and HRCV 229E, and between the different CVLP preparations, the decoration method outlined previously [17] was used. Briefly, a loopful of purified CVLPs or virus was applied to a formvar and carbon coated electron microscope grid and the excess removed after one minute. Before the grid had time to dry it was floated on $10 \mu \mathrm{l}$ of appropriately diluted serum and maintained in a humidifier at room temperature for 30 minutes. Excess fluid was then removed and the grid stained for electron microscopy as outlined above. The decoration titre was taken as the reciprocal of the highest dilution of serum at which antibody (decoration) was found to be attached to at least one of 50 or 100 observed particles.

\section{Polyacrylamide gel electrophoresis}

Polypeptides were separated on $7.5 \%$ and $10 \%$ polyacrylamide slab gels containing sodium dodecyl sulphate (SDS), using the discontinuous system of Laemmli [13]. However, the concentration of mercaptoethanol in the sample buffer was decreased to one per cent in some cases to reduce the number and intensity of extraneous bands. A modification of the method of Herring et al. [10] was used to visualize polypeptide bands by staining with silver nitrate. An additional step involved the overnight soaking of the gels in two changes of methanol, acetic acid, water in the ratio 5:1:5 to fix them and to elute the SDS.

Molecular weights were determined by comparing the electrophoretic mobilities of the unknown polypeptides with those of nine known polypeptide markers ranging in molecular weight from 14,200 ( $\alpha$-lactalbumin) to 205,000 (myosin).

\section{Results \\ Comparison of CVLPs with HRCV 229E and duodenal brush border vesicles}

\section{Comparison of morphology}

Negative contrast electron microscopy showed the Australian and overseas CVLPs studied here to be generally larger and much more pleomorphic than both HRCV 229E particles and the duodenal brush border vesicles (Fig. 1). Differences between the CVLPs and the other two types

Fig. 1. a CVLPs in a faecal extract from an Aboriginal child. Note the two pleomorphic particles surrounded by characteristically shaped surface projections consisting of thin stalks with spherical or oval-shaped knobs at the distal ends (arrows). b Highly purified preparation of CVLPs, such as used for polyacrylamide gel electrophoresis, from a glycerol/ potassium tartrate gradient. The stalks of the CVLP surface projeetions are often not readily visible. c Highly purified preparation of human respiratory coronavirus $229 \mathrm{E}$. Note the typical club- or petal-shaped surface projections (arrows). d Highly purified preparation of duodenal brush border vesicles. Note the differently shaped surface projections compared to the CVLPs (arrows). All of the electron micrographs are at the same magnification and the bar marker represents $100 \mathrm{~nm}$ 

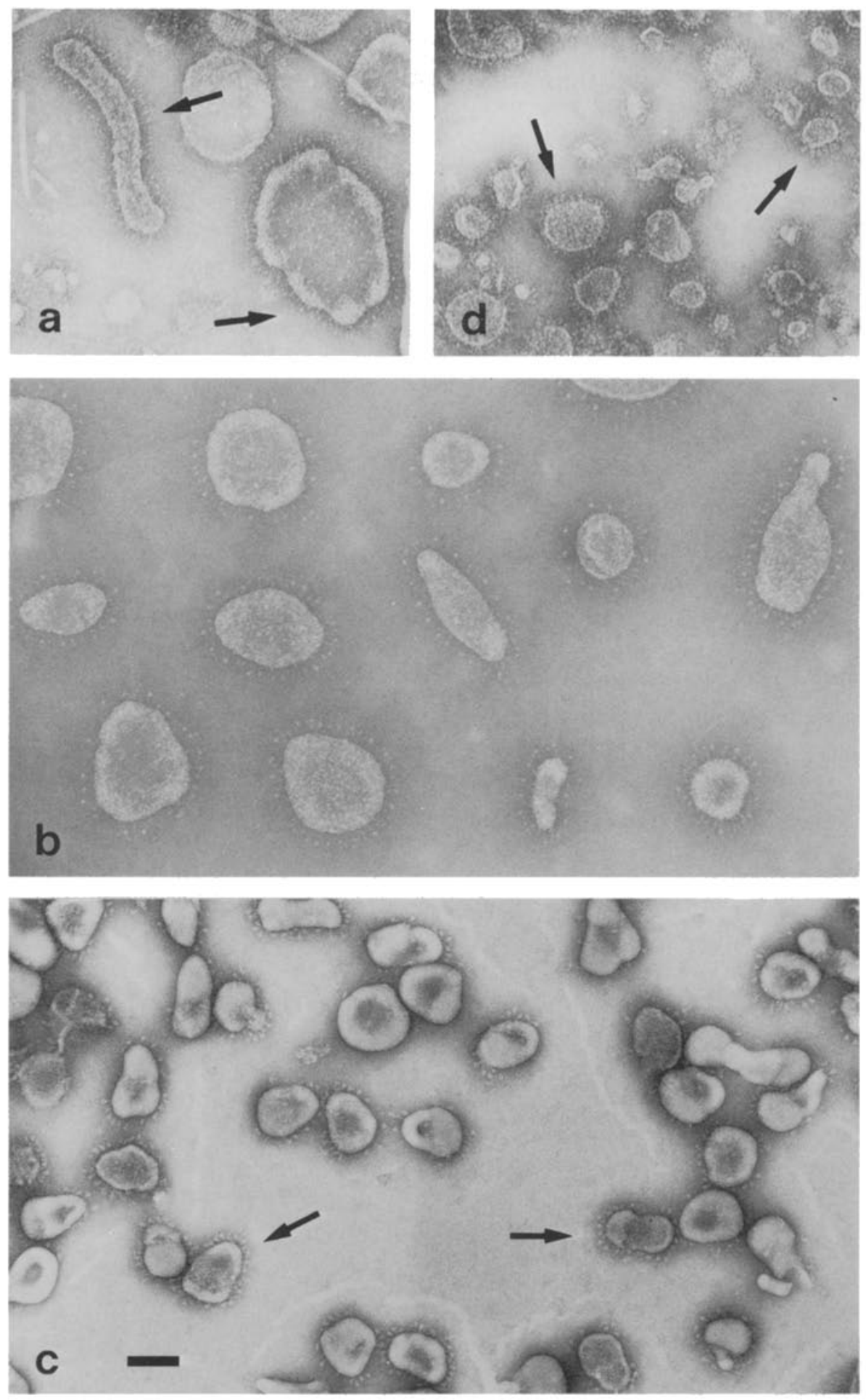

Fig. 1 
of particles were, however, most obvious on comparison of their respective fringes. The surface projections making up the fringe of the CVLPs almost invariably appeared to be slightly longer and were composed of very thin stalks with spherical or oval-shaped knobs at the distal ends. The total length was usually about $22-28 \mathrm{~nm}$ (Fig. $1 \mathrm{a}, \mathrm{b}$ ). Very occasionally Tshaped projections were attached to these knobs or particles appeared to possess two rows of stalks and knobs as reported previously [18].

The fringe of HRCV $229 \mathrm{E}$ particles on the other hand was composed of the typical club-or petal-shaped surface projections approximately $20 \mathrm{~nm}$ long (Fig. 1 c). That of the duodenal brush border vesicles usually appeared to be more compact, with often closely-spaced petal-shaped or rectangular surface projections $12-18 \mathrm{~nm}$ in length (Fig. $1 \mathrm{~d}$ ).

\section{Comparison of polypeptides}

Highly purified preparations of CVLPs (verified by electron microscopy, see Fig. 1 b) from different individual Central Australian Aboriginal children were subjected to electrophoresis on $7.5 \%$ and $10 \%$ polyacrylamide gels, together with highly purified preparations of HRCV $229 \mathrm{E}$ (Fig. $1 \mathrm{c}$ ) and duodenal brush border vesicles (Fig. $1 \mathrm{~d}$ ). Resultant polypeptide profiles are shown in Fig. 2 on a $7.5 \%$ gel, the concentration of acrylamide gel which gave the best overall comparison.

The polypeptide profiles of the CVLPs proved to be very different from that of HRCV $229 \mathrm{E}$, although possibly because of the use of the direct and more sensitive silver staining, several more than the expected 5-7 polypeptide bands [20] were observed on the HRCV 229E profile (Fig. 2). Approximately 38-48 bands were observed on the polypeptide profiles of the CVLPs (Figs. 2 and 3 ).

The polypeptide profile of the duodenal brush border vesicles also differed substantially, although not as much as that of HRCV 229E, from those of the CVLPs with only approximately 20 bands being observed (Fig. 2). Specific differences could be seen for example in the high molecular weight polypeptide region above molecular weight 200,000 , in the region around molecular weight 60,000 , and in the region below molecular weight 35,000 . The highest molecular weight polypeptide observed on the CVLP profiles was one of approximately 220,000 , and that only on the 1983 CVLP profile, whereas polypeptides of molecular weight approximately 250,000 and approximately 300,000 as well as one of molecular weight approximately 230,000 were observed on the duodenal brush border vesicle profile (Figs. 2 and 3 ). Fewer polypeptide bands than on the CVLP profiles were apparent on the brush border vesicle profile in the region around moleeular weight 60,000 , and also in the region below molecular weight 35,000 (Figs. 2 and 3 ). 


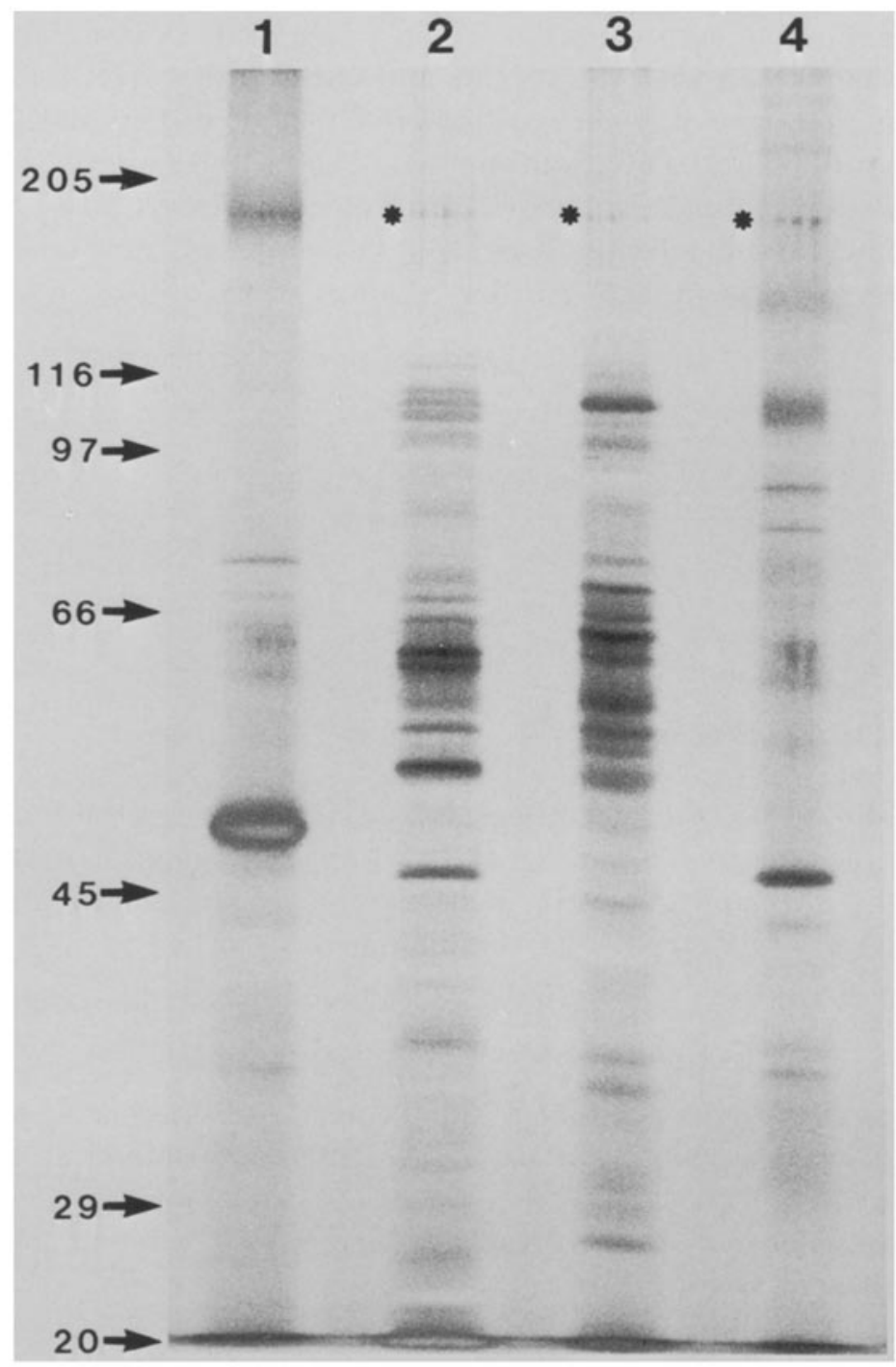

Fig. 2. Comparison on a $7.5 \%$ polyacrylamide gel of the polypeptide profiles of purified HRCV 229E (1), 1982 CVLPs (2), 1984 CVLPs (3), and duodenal brush border vesicles (4). The CVLPs were each from individual Aboriginal children. Migration was from top to bottom and the positions and molecular weights $\left(\times 10^{-3}\right)$ of some of the polypeptide markers are shown on the left. One per cent mercaptoethanol was used in the digestion sample buffer (13) in these preparations. *Extraneous bands which were occasionally visible on some gels 
Antigenic comparison

Hyperimmune serum raised against purified Central Australian CVLPs was reacted with the CVLPs and also purified HRCV 229E, and hyperimmune serum against purified HRCV $229 \mathrm{E}$ was similarly reacted with the two agents. The resultant homologous and heterologous decoration titres obtained are shown in Table 1. Anti CVLP and anti HRCV 229E pre-inoculation decoration titres of sera from mice used to prepare these antisera were 2 or less than 2.

Table 1. Antigenic comparison of CVLPs and HRCV 229E

\begin{tabular}{|c|c|c|}
\hline \multirow[t]{2}{*}{ Agent } & \multicolumn{2}{|c|}{ Decoration titre of antiserum prepared against } \\
\hline & Central Australian CVLPs & HRCV $229 \mathrm{E}$ \\
\hline $\begin{array}{l}\text { Central Australian } \\
\text { CVLPs }\end{array}$ & $20,000^{*}$ & 20 \\
\hline HRCV 229E & 50 & $100,000 *$ \\
\hline
\end{tabular}

The 400- and 5,000-fold differences in titre between the homologous and heterologous reactions with the two antisera, suggest that there is little if any antigenic similarity between the Central Australian CVLPs and HRCV 229E. Too little of the duodenal brush border vesicle preparation was available for antigenic comparisons.

\section{Buoyant density determinations}

The buoyant density of Central Australian CVLPs in sucrose was found to be $1.22 \mathrm{~g} \mathrm{~cm}^{-3}$, while that of HRCV $229 \mathrm{E}$, determined at the same time, was found to be $1.17 \mathrm{~g} \mathrm{~cm}^{-3}$. Identical values were determined for the buoyant density of CVLPs obtained from two different individuals in two different years.

\section{Comparison of different CVLPS}

Antigenic comparison of Central Australian CVLPs

Antisera raised against purified CVLPs from several different Central Australian Aboriginal children in each of 1982, 1983 and 1984 were reacted with the CVLPs used to raise them, and also against the CVLPs obtained in the other two years. The resulting homologous and heterologous decoration titres are shown in Table 2 , and from the use of these polyclonal sera the three different preparations of CVLPs appear to be antigenically identical. Preinoculation decoration titres of sera from the mice used to prepare these antisera were 2 or less than 2. 
Table 2. Antigenic comparison of CVLPs from different Central Australian Aborigines. Specimens obtained in 1982, 1983, and 1984

\begin{tabular}{|c|c|c|c|}
\hline \multirow[t]{2}{*}{ CVLPS } & \multicolumn{3}{|c|}{ Decoration titre of antiserum against CVLPs obtained in } \\
\hline & 1982 & 1983 & 1984 \\
\hline 1982 & $2,000^{*}$ & 1,000 & 1,000 \\
\hline 1983 & 2,000 & $1,000^{*}$ & 1,000 \\
\hline 1984 & 2,000 & 1,000 & $1,000^{*}$ \\
\hline
\end{tabular}

Identical titres to those shown in Table 2, each corresponding to the antiserum used, were obtained with all three of the Central Australian CVLP preparations compared by polyacrylamide gel electrophoresis as described below. Titres for the reverse reactions could not be obtained in these cases because of insufficient CVLPs being available to raise the appropriate antisera.

\section{Comparison of polypeptides}

Highly purified preparations of CVLPs (Fig. 1 b) obtained from different individual Central Australian Aboriginal children in 1982, 1983, and 1984 were subjected to electrophoresis on $7.5 \%$ and $10 \%$ polyacrylamide gels. The polypeptide profiles obtained on a $7.5 \%$ gel are shown in lanes $1-3$ in Fig. 3 . The result of electrophoresis of a highly purified preparation of morphologically identical CVLPs from a Vietnamese immigrant to Australia (Table 3) is shown in lane 4, Fig. 3.

It can be seen that although possibly antigenically identical and although the polypeptide profiles of the three Central Australian CVLPs can be considered to share some basic overall similarity, the profiles differ substantially in detail. This is particularly evident in the case of the 1983 CVLPs, the polypeptide profile of which exhibits a number of extra bands at molecular weights of approximately 120,000-160,000, not evident on the profiles of the other two Central Australian CVLPs. The polypeptide profile of the 1982 CVLPs resulted in at least 39 bands, that of the 1983 CVLPs in at least 48 , and that of the 1984 CVLPs in at least 38.

Careful analysis of the $7.5 \%$ and $10 \%$ (not shown) gels indicated that there were many bands common to the polypeptide profiles of the three different Central Australian CVLPs, although occasionally they differed in intensity between the three profiles. For example, major bands on two of the profiles were present as more minor ones on the other. Of the numerous polypeptides not common, both major and minor, many differed from ones in the other two CVLPs by very little in terms of molecular weight. These small differences could prove not to be particularly sig- 


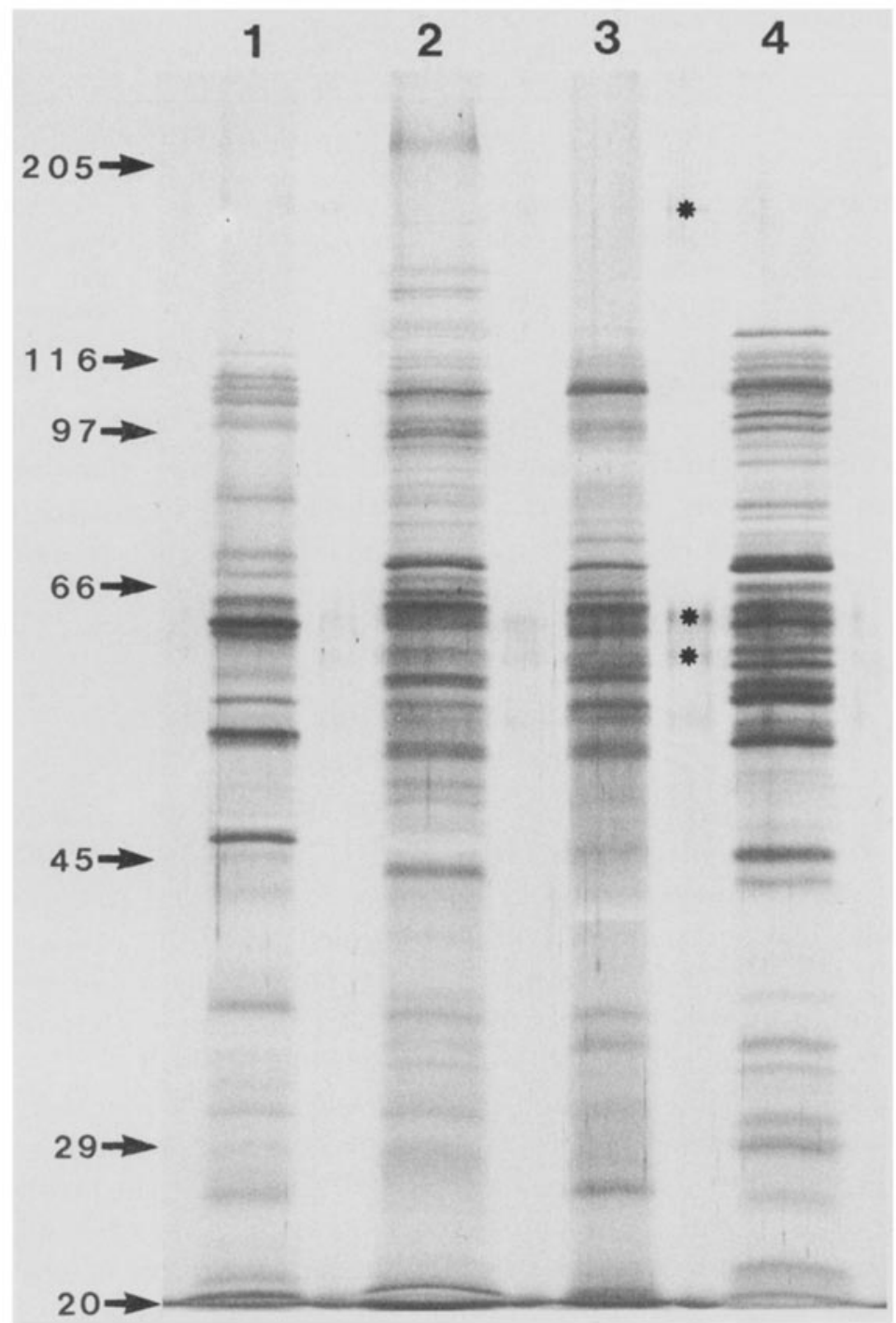

Fig. 3. Comparison of the polypeptide profiles of purified CVLPs on a $7.5 \%$ polyacrylamide gel. Central Australian CVLPs from individual Aboriginal children from 1982 (1), from 1983 (2), and from 1984 (3). CVLPs from a Vietnamese immigrant to Australia (4). Migration was from top to bottom and the positions and molecular weights $\left(\times 10^{-3}\right)$ of some of the polypeptide markers are shown on the left. * Extraneous bands which were occasionally visible on some gels

nificant as many such polypeptides could be equivalent in different CVLPs.

Electrophoresis of the Vietnamese CVLPs resulted in at least 46 polypeptide bands. The polypeptide profile of these CVLPs differed substan- 
Table 3. Decoration titres of anti-Central Australian CVLP serum against CVLPs from different areas

\begin{tabular}{|c|c|c|c|}
\hline Origin of CVLPs & $\begin{array}{l}\text { Age of } \\
\text { individual }\end{array}$ & $\begin{array}{l}\text { Year } \\
\text { collected }\end{array}$ & $\begin{array}{l}\text { Decoration } \\
\text { antibody titre }\end{array}$ \\
\hline $\begin{array}{l}\text { Central Australia } \\
\text { (Aborigines) }\end{array}$ & Children & 1984 & $1,000^{\mathrm{a}}$ \\
\hline $\begin{array}{l}\text { Kalgoorlie, Western } \\
\text { Australia (Aborigines) }\end{array}$ & $\begin{array}{l}\text { (a) } 1 \text { year } \\
\text { (b) } 18 \text { months }\end{array}$ & $\begin{array}{l}1976 \\
1975\end{array}$ & $\begin{array}{r}1,000 \\
500\end{array}$ \\
\hline $\begin{array}{l}\text { Kalgoorlie, Western } \\
\text { Australia (Europeans) }\end{array}$ & $\begin{array}{l}\text { (a) } 2 \text { years } \\
\text { (b) } 3 \text { years }\end{array}$ & $\begin{array}{l}1975 \\
1975\end{array}$ & $\begin{array}{l}400 \\
500\end{array}$ \\
\hline $\begin{array}{l}\text { Fitzroy Crossing, } \\
\text { Western Australia } \\
\text { (Aborigines) }\end{array}$ & $\begin{array}{l}\text { (a) } 11 \text { years } \\
\text { (b) } 15 \text { years }\end{array}$ & $\begin{array}{l}1977 \\
1977\end{array}$ & $\begin{array}{l}100 \\
100\end{array}$ \\
\hline $\begin{array}{l}\text { Vietnamese immigrants } \\
\text { to Australia }\end{array}$ & $\begin{array}{l}\text { (a) } 16 \text { years } \\
\text { (b) } 18 \text { years } \\
\text { (c) } 21 \text { years }\end{array}$ & $\begin{array}{l}1978 \\
1978 \\
1978\end{array}$ & $\begin{array}{l}100 \\
200 \\
200\end{array}$ \\
\hline India (Vellore) & $\begin{array}{l}\text { (a) adult } \\
\text { (b) adult }\end{array}$ & $\begin{array}{l}1976 \\
1979\end{array}$ & $\begin{array}{l}100 \\
100\end{array}$ \\
\hline $\begin{array}{l}\text { Kiribati } \\
\text { (Pacifre Ocean) }\end{array}$ & $\begin{array}{l}\text { (a) young adult } \\
\text { (b) young adult }\end{array}$ & $\begin{array}{l}1979 \\
1979\end{array}$ & $\begin{array}{r}50 \\
100\end{array}$ \\
\hline $\begin{array}{l}\text { South Africa, Lesotho } \\
\text { (rural black) }\end{array}$ & child & 1985 & 50 \\
\hline
\end{tabular}

tially in detail from those of the three Central Australian CVLPs, although it could be considered to share some basic overall similarity with them, including a number of common bands (Fig. 3). Some antigenic difference was also apparent between the Vietnamese CVLPs and the Central Australian ones (see below and Table 3). It can also be seen from Fig. 3 that in common with the 1982 and 1984 Central Australian CVLPs, very few polypeptide bands are apparent above molecular weight 125,000 on the Vietnamese CVLP profile.

Antigenic comparison of Central Australian CVLPs with those from other areas

It was felt that it would be of interest to obtain some idea of the antigenic similarity or differenee between Central Australian CVLPs and morphologically identical ones from different areas of Australia and overseas. Therefore the homologous decoration titre of one of the prepared 
antisera to Central Australian particles (1984) was compared with titres obtained with this serum, and purified CVLPs from various individuals from the different areas as shown in Table 3. Unfortunately sufficient CVLPs were not available from the non-Central Australian specimens to raise antisera and so the reverse titres could not be obtained.

The results shown in Table 3 indicate antigenic similarity between the Central Australian CVLPs and those from the Kalgoorlie (Western Australia) Aborigines and probably also those from the Kalgoorlie Europeans. Kalgoorlie is approximately $1,500 \mathrm{~km}$ south west of Alice Springs (Central Australia). It is also of interest to note that the Kalgoorlie CVLPs and the Central Australian ones used to raise the antiserum were obtained approximately 9 years apart.

Some antigenic difference is, however, suggested between the Central Australian CVLPs and those from Fitzroy Crossing in Western Australia, approximately $1,000 \mathrm{~km}$ north west of Alice Springs. Some antigenic difference is also indicated between the Central Australian CVLPs and those from India (Vellore), Kiribati (Pacific Ocean), South Africa (Lesotho), and probably also those from the Vietnamese immigrants to Australia.

\section{Discussion}

Morphologically the so-called CVLPs we have by far most frequently observed in faecal specimens from Australian Aborigines and Europeans can be considered to be coronavirus-like, and very similar particles have been observed in many different countries. They closely resemble the CVLPs propagated by Caul and Egglestone [5]. However, there have always appeared to be consistently observed differences in the morphology of the surface projections between these CVLPs and the classical coronaviruses, as has been pointed out previously $[14,18]$, and our present results further support this. Other differences have been apparent in the usually larger size and much greater pleomorphism of the CVLPs [14], and our results are also in keeping with this. Members of the recently proposed torovirus group $[3,23]$ appear to differ from the CVLPs in these morphological properties as well.

Comparison of the polypeptide profiles of the Central Australian CVLPs with that of HRCV 229E has shown the CVLPs almost certainly not to be coronaviruses. This is underlined by comparison of the CVLP profiles with published data on the polypeptides of other coronaviruses [20]. Consequently therefore, the lack of antigenic similarity we found between the CVLPs and HRCV 229E is not surprising.

On the basis of the apparent polypeptide structure of members of the torovirus group [23] the Australian CVLPs also appear not to fit into this group. 
Comparison of the CVLP polypeptide profiles with that of duodenal brush border vesicles suggests that the CVLPs are probably not duodenal brush border vesicles. This is supported by our morphological findings which indicate differences between the CVLPs and the brush border vesicles, particularly in the size and structure of the surface projections.

Very little work has been carried out on the antigenic similarities and differences between the CVLPs, morphologically dissimilar to the classical coronaviruses, that have been obtained from different areas. We have extended our earlier very preliminary findings of indications of antigenic differences between the Central Australian and overseas CVLPs, and antigenic similarity as well as difference between the Central Australian CVLPs and those from other distant locations within Australia [17]. However, as we were not able to obtain titres in both directions for the Central Australian CVLPs and those from other areas, our findings cannot be taken as being completely definitive at this stage.

The previous finding that the serum antibody levels to the CVLPs followed the excretion rates in the populations tested in Australia has supported the contention that they are infectious agents [17]. However, determination of the type of agent that they might be has been made more difficult by the relative lack of uniformity between the polypeptide profiles of the three different but possibly antigenically identical Central Australian CVLPs, although this does lead to the suggestion that these particles may not be viruses. It has generally been found, that although they may differ in detail, the polypeptide profiles of different members of a virus group usually show relatively strong evidence of a basic overall similarity.

On further comparison with viruses the number of polypeptides apparently making up the CVLPs is greater than that for poxviruses. Poxviruses, so far the most complex of the animal viruses, may possess up to approximately 35 structural polypeptides [2], compared to possibly at least 38 for the Central Australian CVLPs.

It is of course a possibility that some of the multiplicity and variation of polypeptide bands found on analysis of the CVLPs may have arisen through proteolysis of a smaller number of high molecular weight proteins. The use of such a sensitive detection system as silver staining and the fact that a direct or total staining method was used could also have contributed to the multiplicity of polypeptide bands observed. This being particularly pertinent if the CVLPs were enveloped viruses, as many such viruses are known to pick up small amounts of host polypeptides during assembly, and extra bands may be visible on their polypeptide profiles if a sensitive direct staining method was used. Proteolysis, in conjunction with the use of the sensitive silver stain, and the use of sensitive direct staining rather than radiolabelling, could also at least partly account for 
the larger than expected number of bands on the HRCV 229E polypeptide profile. In the case of the CVLPs the use of Western blotting and immunolabelling should be of assistance in sorting out at least some of the many polypeptide components.

Suggestions have been made that enteric pleomorphic fringed particles, such as the Australian CVLPs are, could be mycoplasmas [3]. From a general consideration of the relative size and pleomorphism of the Australian CVLPs and mycoplasmas there are definite similarities. Although on comparison of our findings on the CVLPs with published data on mycoplasmas, particularly in relation to morphology of the outer fringe [22 and R. D. Schnagl unpublished observations] and structural polypeptide profiles $[1,8]$, the two types of particles appear less similar.

It is also a consideration that the CVLPs could be a new type of agent, although it is possible that they may just be fragments of a larger agent such as one of the parasites. Parasites are often particularly prevalent in the populations with high rates of excretion of CVLPs [19]. However, before their identity (or identities) can be firmly established it is clear that much more work is required on the characterisation of CVLPs dissimilar to the classical coronaviruses.

\section{Acknowledgments}

We gratefully acknowledge the assistance of Dr. J. Erlich, the staff of the Pathology Laboratory, Alice Springs Hospital, Dr. J. R. L. Forsyth, and the Community Health Service and State Health Laboratory Services of Western Australia in obtaining faecal specimens. We also acknowledge the financial support of the National Health and Medical Research Council of Australia.

\section{References}

1. Anderson $\mathrm{H}$, Christiansen $\mathrm{G}$, Christiansen C (1984) Electrophoretic analysis of proteins from Mycoplasma capricolum and related serotypes using extracts from intact cells and from minicells containing cloned mycoplasma DNA. J Gen Microbiol 130: 14091418

2. Arita M, Tagaya I (1980) Virion polypeptides of poxviruses. Arch Virol 62: 209-225

3. Beards GM, Brown DWG, Green J, Flewett TH (1986) Preliminary characterisation of torovirus-like particles of humans: comparison with Berne virus of horses and Breda virus of calves. J Med Virol 20: 67-78

4. Caul EO, Ashley CR, Egglestone ST (1977) Recognition of human enteric coronaviruses by electron microscopy. Med Lab Sci 34: 259-263

5. Caul EO, Egglestone SI (1977) Further studies on human enteric coronaviruses. Arch Virol 54: 107-117

6. Caul EO, Paver WK, Clarke SKR (1975) Coronavirus particles in faeces in patients with gastroenteritis. Lancet i: 1192

7. Dourmashkin RR, Davies HA, Smith HA, Bird RG (1980) Are coronavirus-like particles seen in diarrhoeic stools really viruses? Lancet ii: 971-972

8. Feldner $J$, Bredt $W$ (1983) Analysis of polypeptides of mutants of Mycoplasma pneumoniae that lack the ability to haemadsorb. J Gen Microbiol 129: 841-848 
9. Gerna G, Passarani N, Battaglia M, Rondanelli EG (1985) Human enteric coronaviruses: antigenic relatedness to human coronavirus $\mathrm{OC} 43$ and possible etiologic role in viral gastroenteritis. $J$ Infect Dis 151: 796-803

10. Herring AJ, Inglis NF, Ojeh CK, Snodgrass DR, Menzies JD (1982) Rapid diagnosis of rotavirus infection by direct detection of viral nucleic acid in silver-stained polyacrylamide gels. J Clin Microbiol 16: 473-477

11. Kapikian AZ, Gerlin JF, Wyatt RG, Thornhill TS, Chanock RM (1973) Density in caesium chloride of the $27 \mathrm{~nm}$ " 8 Flla" particle associated with acute non-bacterial gastroenteritis: determination by ultacentrifugation and immune electron microscopy. Proc Soc Exp Biol Med 142: 874-877

12. Kessler M, Acuto O, Storelli C, Murer H, Muller M, Semenza G (1978) A modified procedure for the rapid preparation of efficiently transporting vesicles from small intestinal brush border membranes. Their use in investigating some properties of $D$ glucose and chloline transport systems. Biochim Biophys Acta 506: 136-154

13. Laemmli UK (1970) Cleavage of structural proteins during the assembly of the head of bacteriophage T4. Nature 227: 680-685

14. MacNaughton MR, Davies HA (1981) Human enteric coronaviruses. Brief review. Arch Virol 70: 301-313

15. Mathan M, Mathan VI, Swaminathan SP, Yesudoss S, Baker SJ (1975) Pleomorphic virus-like particles in human faeces. Lancet i: 1068-1069

16. Resta S, Luby JP, Rosenfeld CR, Siegel JD (1985) Isolation and propagation of a human enteric coronavirus. Science 229: 978-981

17. Schnagl RD, Greco T, Morey F (1986) Antibody prevalence to human enteric coronavirus-like particles and indications of antigenic differences between particles from different areas. Arch Virol 87:331-337

18. Schnagl RD, Holmes IH, MacKay-Scollay EM (1978) Coronavirus-like particles in Aboriginals and non-Aboriginals in Western Australia. Med J Aust 1: 307-309

19. Schnagl RD, Morey F, Holmes IH (1979) Rotavirus, coronavirus-like particles, bacteria and parasites in Central Australia. Med J Aust 2: 115-118

20. Siddell SG, Wege H, Ter Meulen V (1982) The structure and replication of coronaviruses. In: Cooper M et al (eds) Current topics in microbiology and immunology, vol 99. Springer, Berlin Heidelberg New York, vol 99, pp 131-163

21. Sitbon M (1985) Human-enteric-coronavirus-like particles (CVLP) with different epidemiological characteristics. J Med Virol 16: 67-76

22. Takayama H, Katsumoto T, Ohno K, Nakaso A, Tagaki A, Kimura G (1983) In situ electron microscopic observation of negatively stained tissue culture cells contaminated with mycoplasmas. J Gen Microbiol 129: 3379-3384

23. Weiss M, Horzinek MC (1987) The proposed family Toroviridae: agents of enteric infections. Brief review. Arch Virol 92: 1-15

Authors' address: Dr. R. D. Schnagl, Department of Microbiology, La Trobe University, Bundoora, Victoria, 3083, Australia. 